\title{
Heart rate and blood lactate responses during the cross-country test of 2-star to 5-star eventing competitions
}

\author{
K. Kirsch ${ }^{1,2^{*}}$, S. Horstmann ${ }^{2}$, H. Holzhausen ${ }^{3}$, D. Serteyn ${ }^{1}$ and C. Sandersen ${ }^{1}$ \\ 1 University of Liège, Clinical Department of Companion Animals and Horses, Boulevard de Colonster 20 B41, 4000 Sart Tilman, Belgium; \\ ${ }^{2}$ German Olympic Committee for Equestrian Sports, Freiherr-von-Langen-Str. 15, 48231 Warendorf, Germany; ${ }^{3}$ Olympic Centre Warendorf, \\ Dr.-Rau-Alle 32, 48231 Warendorf, Germany; kkirsch@fn-dokr.de
}

Received: 4 December 2018 / Accepted: 26 February 2020

() 2020 Wageningen Academic Publishers

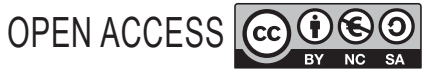

RESEARCH ARTICLE

\begin{abstract}
The objective of this retrospective study was to evaluate the physiological demands of cross-country competitions at different levels. Heart rates (HR) and post exercise blood lactate concentrations (LAC) measured between 2010 and 2019 in response to 1,463 cross-country competitions (437 at 2-star, 703 at 3-star, 313 at 4-star and 10 at 5-star level) in 294 horses were analysed. The effect of competition level, mean velocity, height profile, total distance, number of jumping efforts, climate, age, sex, percentage of Thoroughbred blood and performance level on HR, LAC, HR recovery and LAC disappearance rates was evaluated by Linear Mixed Effects Models. Mean HR and LAC significantly increased from 2 -star to 4 -star level $(P<0.001)$. Each $30 \mathrm{~m} / \mathrm{min}$ increase in mean velocity was associated with a 3 beats/min increase in $\operatorname{HR}(P<0.001)$ and a $41 \%$ increase in LAC $(P<0.001)$ and each $30 \mathrm{~m}$ increase in cumulative elevation with a 2 beats/min increase in HR $(P<0.001)$ and a $32 \%$ increase in LAC $(P<0.001)$. Each $20 \mathrm{~m}$ increase in mean distance per jumping effort was associated with a 1 beat $/ \mathrm{min}$ decrease in $\mathrm{HR}(P<0.01)$ and a $13 \%$ decrease in LAC $(P<0.001)$. Compared to Warmbloods, horses with $75 \%$ Thoroughbred blood had 4 beats/ min lower HRs $(P<0.05)$ and $34 \%$ lower LAC values $(P<0.001)$. Each 5 years increase in age was associated with a 4 beats/min decrease in HR $(P<0.001$, only in mares $)$ and an $11 \%$ decrease in LAC $(P<0.01)$. The HRs during the first 3 minutes of recovery were higher at warmer and more humid conditions $(P<0.05)$. The rate of LAC disappearance was higher in horses with higher percentages of Thoroughbred blood $(P<0.05)$.
\end{abstract}

Keywords: horses, equine, exercise, heart rate recovery, GPS

\section{Introduction}

The cross-country phase of international eventing competitions is considered to be one of the most physically demanding equestrian disciplines and maintenance of the horse's health and well-being represents a unique challenge. Profound knowledge of the physiological demands placed on the horses during the cross-country test is therefore essential for all those concerned with the training, care and management of eventing horses.

The intensity of exercise during the cross-country test depends on several factors that can be categorised either as external or internal. The external or absolute workload is the objectively measurable physical work performed by the horse and mainly defined by the level and format of the competition (Table 1).

The levels are ranked by a star system ranging from low level 1-star (CCI1*) to high level 5-star (CCI5*) competitions which require the maximum level of training and experience. The cross-country course of short format (CCI-S) competitions is shorter, although the level of difficulty in long (CCI-L) and short format competitions at the same level is similar (Table 1). Even though the distances to be covered, the number and dimension of jumping efforts as well as the required speeds are similar for competitions at the same level and format, additional factors, such as steep uphill gradients may considerably increase the external workload. Moreover, identical external workloads may 
Table 1. Required distances, speeds, number and dimensions of jumping efforts and distance per jumping efforts for the crosscountry test of international eventing competitions from $\mathrm{CCl}^{*}$ to $\mathrm{CCl}^{*}$ level for short (CCl-S) and long format (CCl-L) competitions as determined by the Fédération Equestre Internationale (FEI Eventing Rules, 2020).

\begin{tabular}{|c|c|c|c|c|c|c|c|c|c|}
\hline \multirow[t]{2}{*}{ Level } & \multicolumn{2}{|c|}{ Distance (m) } & \multirow{2}{*}{$\begin{array}{l}\text { Speed }(\mathrm{m} / \mathrm{min}) \\
\text { mean }\end{array}$} & \multicolumn{2}{|c|}{ Number of efforts } & \multicolumn{2}{|c|}{ Distance/efforts (m) } & \multicolumn{2}{|c|}{ Max. dimensions of efforts (m) } \\
\hline & $\min$. & $\max$. & & $\min$. & $\max$. & $\min$. & $\max$. & height & spread \\
\hline $\mathrm{CCl} 2^{*}-\mathrm{S}$ & 2,600 & 3,120 & 520 & 25 & 30 & 87 & 125 & 1.10 & 2.10 \\
\hline $\mathrm{CCl} 2^{*}-\mathrm{L}$ & 3,640 & 4,680 & 520 & 25 & 30 & 121 & 187 & 1.10 & 2.10 \\
\hline $\mathrm{CCl} 3^{*}-\mathrm{S}$ & 3,025 & 3,575 & 550 & 27 & 32 & 95 & 132 & 1.15 & 2.40 \\
\hline $\mathrm{CCl}^{*}-\mathrm{L}$ & 4,400 & 5,500 & 550 & 30 & 35 & 126 & 183 & 1.15 & 2.40 \\
\hline $\mathrm{CCl} 4^{*}-\mathrm{S}$ & 3,420 & 3,990 & 570 & 30 & 35 & 98 & 133 & 1.20 & 2.70 \\
\hline $\mathrm{CCl} 4^{*}-\mathrm{L}$ & 5,700 & 6,270 & 570 & 35 & 40 & 143 & 179 & 1.20 & 2.70 \\
\hline $\mathrm{CCl}^{*}-\mathrm{L}$ & 6,270 & 6,840 & 570 & 40 & 45 & 139 & 171 & 1.20 & 3.00 \\
\hline
\end{tabular}

elicit considerably different internal or relative workloads in horses at different levels of training and fitness.

The first serious indications of the need for better scientific understanding of the physiological demands of eventing were seen at the 1992 Olympic Games in Barcelona. Several horses were affected by the hot climate and exhibited signs of heat exhaustion linked to exerciseassociated hyperthermia (Marlin, 2009). As a result of these observations, a tremendous amount of research has been conducted prior to the 1996 Olympic Games in Atlanta which allowed to derive scientific recommendations for officials, trainers and riders on measures to ensure the horse's welfare and safety during eventing competitions especially under hot and humid conditions (Jeffcott and Kohn, 1999). However, since the 1996 Olympic Games in Atlanta, a fundamental change of the sport of eventing has occurred. In the classical eventing competition, the speedand-endurance test on the second day of the competition included a short roads-and-tracks phase (3,520-4,400 m at $220 \mathrm{~m} / \mathrm{min})$, followed by a steeplechase phase $(1,920$ $3,105 \mathrm{~m}$ at $690 \mathrm{~m} / \mathrm{min}$ ), which in turn was followed by a long roads-and-tracks phase (4,000-7,200 m at $220 \mathrm{~m} /$ min). The second roads-and-tracks phase was followed by a 10 min mandatory veterinary inspection during which it was determined whether the horses were sound and fit to compete in the final cross-country phase. On the occasion of the Olympic Games in Athens 2004, the classical competition format was modified by excluding the roadsand-tracks and steeplechase phases while retaining only the cross-country phase and the short format cross-country test was introduced. There is currently no published information that comprehensively describes the physiological response to short format cross-country tests at different levels (Marlin, 2014). It therefore remains unknown how the modification of the competition requirements may have changed the physiological demands, what implications this modification may entail for the type of horses that will be most suited for modern eventing competitions and what should be considered as appropriate training (Marlin, 2014).

The objective of this study therefore was to retrospectively analyse heart rate (HR) and blood lactate concentrations (LAC) obtained from a large number of horses during crosscountry tests on various events over a period of several years in order to evaluate which relative workloads horses encounter during cross-country competitions at different levels and how the physiological demands are affected by external (competition level and format, track length, number of jumping efforts, ridden speed, elevation gain, climate conditions) and internal factors (age, sex, amount of Thoroughbred blood, performance level).

\section{Material and methods}

\section{Horses and competitions}

A total of 294 horses (7 stallions, 107 mares, 180 geldings) aged between 6 and 20 years and of various levels of experience and performance were sampled each on 1 to 30 occasions between 2010 and 2019 during the cross-country test of 212 eventing competitions that took place during 121 different events at 36 different venues in Europe. The competitions were held under the rules of the Fédération Équestre Internationale (FEI) and ranged from 2-star to 5-star level. Only horses that finished the cross-country test were included for analysis.

The horses which were selected to be monitored belonged to 131 riders qualified for different categories of the German national Event squad (Olympic Squad, Perspective Squad, Youth Squad U21 and U18). The data collection was carried out as part of the 'performance monitoring programme' of the German Olympic Committee for Equestrian Sports 
(DOKR) the aim of which is to promote long-term health and performance of elite eventing horses by providing performance diagnostic measures.

\section{Measurement of heart rate, GPS data, height profile and climatic conditions}

The HR was recorded throughout the cross-country phase by a HR sensor (Polar Equine T52H or H7, Polar Electro Oy, Kempele, Finland). The HR sensor consisted of a transmitter and two plastic electrodes, with one electrode placed under the girth behind the left elbow and the other placed on the right side of the withers under the saddle. To optimise contact, the horse's coat and skin were wetted with water. The used HR meter has been shown to provide accurate results compared to telemetric electrocardiography in exercising horses (Evans and Rose, 1986).

In order to record the distances covered during the cross-country tests, the horses were additionally equipped with a GPS device (Equipilot, Fidelak $\mathrm{GmbH}$, Kamen, Germany) which was stowed in a pocket on the saddlecloth. It simultaneously served as receiver for the HR data (integrated Polar wireless HR receiver module) and transmitted the recorded HR and GPS data via mobile network. HR and GPS data were recorded at a frequency of $1 \mathrm{~Hz}$. The reliability of the GPS device for simultaneous recording of distance, velocity and $\mathrm{HR}$ of horses exercising on a field track has been previously evaluated (Hebenbrock et al., 2005; Kusunose and Takahashi, 2002). Hebenbrock et al. (2005) found an overall relative variability of $0.68 \%$ for distances measured by the Equipilot compared to a calibrated high precision measuring wheel which corresponds to a deviation of $6.8 \mathrm{~m}$ per $1000 \mathrm{~m}$.

The height profiles of the cross-country courses were evaluated by measuring the distance with a high precision measuring wheel (Feld-Entfernungsmesser T590, PCE Instruments, Meschede, Germany) and the respective altitude with a barometric altimeter (Escape 203, Suunto, Vantaa, Finland). The cumulative elevation was calculated as the sum of every gain in elevation throughout the entire course.

The climate conditions during each event were quantified by estimation of the wet bulb globe temperature (WBGT) index from ambient temperature $\left(\mathrm{T}\right.$ in $\left.{ }^{\circ} \mathrm{C}\right)$ and relative humidity ( $\mathrm{RH}$ in \%) using the approximation proposed by the FEI (FEI Eventing Memorandum, 2015): WBGT = $0.567 \times \mathrm{T}+0.393 \times(\mathrm{RH} / 100 \times 6.105 \times \exp (17.27 \times \mathrm{T} /(237.7+$ $\mathrm{T})))+3.94$. The average temperature and relative humidity during the competition were obtained from a weather website (wetter.com).

\section{Blood sampling and determination of blood lactate concentration}

Venous blood samples were collected 10 and 30 min after the completion of the cross-country test. Blood samples were collected by venipuncture of the jugular vein into $3 \mathrm{ml}$ plastic syringes. LAC was determined immediately after blood sample collection from whole blood by means of a hand-held photometer (Lactate Photometer Plus DP 110, Diaglobal, Berlin, Germany). Therefore, $10 \mu \mathrm{l}$ of the whole blood sample was pipetted within 1 min after sample collection into a cuvette containing haemolysing solution. After measuring a blank value, an enzymatic reaction was started by adding a reagent containing lactate oxidase and peroxidase. The LAC concentration was then determined based on the extinction of the dye produced from the enzymatic reaction.

\section{Data processing}

The mean HR was calculated by averaging the HR data (1 value per second) recorded during the whole cross-country test (from crossing the start to crossing the finish line). Moreover, each of the continuously recorded $H R$ values was assigned to one of 4 different HR zones (zone 1: $\leq 189$ beats/min; zone 2: 190-199 beats/min; zone 3: 200-209 beats/min; zone $4: \geq 210$ beats/min) and the percentage of time spent within each HR zone during the cross-country test was calculated. The HR zones were selected to reflect exercise intensities of approximately <75\%, 75-80\%, 80-90\% and $>90 \%$ of maximum oxygen consumption $\left(\mathrm{VO}_{2 \max }\right)$, assuming an average maximum HR of 220 beats/min and based on the relationship between percentage of maximum $\mathrm{HR}\left(\% \mathrm{HR}_{\max }\right)$ and $\% \mathrm{VO}_{2 \max }$ as described by Evans and Rose (1987): $\% \mathrm{VO}_{2 \max }=1.617 \times \% \mathrm{HR}_{\max }-65.02$.

The mean velocity during the cross-country test was calculated from the distance measured by the GPS device and the duration instead of using the mean GPS velocity because it has been shown that the accuracy of GPS velocity measurements is lower than that of GPS distance and that the GPS velocity generally tends to be lower than the velocity calculated from distance and duration (Hebenbrock et al., 2005; Lindner and Brand, 2020).

To evaluate post exercise HR recovery, the horses HRs during the first $5 \mathrm{~min}$ of recovery from the cross-country test were expressed as percentages of the HR reached at the end of the cross-country test $\left(\mathrm{HR}_{\text {peak }}\right)$. The $\mathrm{HR}_{\text {peak }}$ was calculated by averaging the HR values during the last $5 \mathrm{~s}$ of the cross-country test. Only HRs which were recorded for at least 5 min after the cross-country test were included for analysis. The relationship between HR decrease and recovery time was approximated using the bi-exponential function $\operatorname{HR}(\%)=\mathrm{a}_{\text {fast }} \times \exp \left(-\mathrm{t} / \tau_{\text {fast }}\right)+\mathrm{a}_{\text {slow }} \times \exp \left(-\mathrm{t} / \tau_{\text {slow }}\right)$ $+\mathrm{a}_{0}$ which is a combination of a fast and a slow exponential 
decrease where $\tau_{\text {fast }}$ and $\tau_{\text {slow }}$ are the time constants of the fast and the slow decreases, $\mathrm{a}_{\text {fast }}$ and $\mathrm{a}_{\text {slow }}$ are their respective amplitudes and $\mathrm{a}_{0}$ is the basic offset. Since the horses were walked during recovery, the basic offset equals the HR during walk and was set to 75 beats/min. Recovery HRs at 60 s, 120 s, 180 s, $240 \mathrm{~s}$ and $300 \mathrm{~s}$ of recovery were calculated by means of the obtained regression equations.

To evaluate LAC removal following exercise, the differences between LAC concentrations measured $10 \mathrm{~min}\left(\mathrm{LAC}_{10}\right)$ and $30 \mathrm{~min}\left(\mathrm{LAC}_{30}\right)$ post-exercise were calculated and extrapolated to LAC disappearance rates $(\triangle \mathrm{LAC})$ per hour. The relationship between $\triangle \mathrm{LAC}$ and $\mathrm{LAC}_{10}$ values was approximated using a saturation growth-rate equation $\left(\triangle \mathrm{LAC}(\mathrm{mmol} / \mathrm{l} / \mathrm{h})=\alpha \times \mathrm{LAC}_{10} /\left(\beta+\mathrm{LAC}_{10}\right) \cdot \mathrm{LAC}_{30}\right.$ values were only determined if $\mathrm{LAC}_{10}$ was $\geq 4 \mathrm{mmol} / \mathrm{l}$.

The competition performance of each horse was rated following the FEI World Eventing Ranking System (www. fei.org). Depending on the level and format, the number of competitors and the results from each discipline, a certain number of points was awarded for the final ranking in each competition. The horse's scores over each season were added up to achieve a total performance score for each competitive season.

\section{Statistical analyses}

Linear Mixed Effects Models (LMM) with $\mathrm{LAC}_{10}, \triangle \mathrm{LAC}$, mean $H R$ and recovery HRs as respective response variables were created using the 'Imer' function in R (Bates et al., 2015). The majority of horses were sampled repeatedly on various occasions with some horses sampled more frequently than others. Consequently, each horse made different contributions to the data and independence of observations could not be assumed. In order to account for multiple measurements of the same horse on different occasions and of several horses on the same occasion, horse as well as event nested within competition venue were included as random intercepts. The fixed-effects variables, tested in the models, were: sex (mare/stallion/gelding), age (years), proportion of Thoroughbred blood (\%), competition level (2-star/3-star/4-star/5-star), competition format (short/long), mean velocity $(\mathrm{m} / \mathrm{min})$, total distance $(\mathrm{m})$, number of jumping efforts, cumulative elevation gain (m), WBGT and FEI world ranking score. Significant interactions between predictors were evaluated by calculating JohnsonNeyman intervals using the 'sim_slopes' function (Long, 2019). Collinearity between predictors was evaluated by calculating variance inflation factors (VIF) using the 'vif. lme' function (Monette, 2015). VIFs $<3$ were considered to be acceptable to retain the respective variable in the model (Zuur et al., 2010). Full models including all fixed effects were reduced by sequentially dropping fixed effects based on Akaike's information criterion (AIC) which was used to assess relative model fit. Only predictors that improved the AIC by more than 2 units $(\triangle \mathrm{AIC}>2)$ were retained in the model (Arnold, 2010; Burnham and Anderson, 2002). The significance of the fixed effects was evaluated by comparing full models to models without the respective fixed effect by means of likelihood ratio tests using the 'anova' function (Bates et al., 2015). In case of significance $(P \leq 0.05)$, pairwise comparisons between categories (level, sex) were done by General Linear Hypothesis Tests with Bonferroni-Holm correction using the 'glht' function (Hothorn et al., 2008). Marginal and conditional coefficients of determination $\left(\mathrm{r}^{2}\right)$ were calculated for each model using the 'r.squaredGLMM' function (Barton, 2018). The marginal $r^{2}$ describes the proportion of variance explained by the fixed factors and the conditional $\mathrm{r}^{2}$ describes the proportion of variance explained by both the fixed and random factors. Estimated marginal means were calculated using the 'emmeans' function (Lenth, 2019). Normality of the residual distribution was checked with the normal probability plot of the residuals.

All figures and statistical analyses were performed using Excel (Microsoft Excel 2013, Microsoft Corporation, Redmond, WA, USA) and R ( $\mathrm{R}$, version 3.4.3, The $\mathrm{R}$ Foundation, Vienna, Austria). Regression analyses of the recovery HRs and $\triangle \mathrm{LAC}$ were carried out in Excel using the integrated Solver Add-In.

\section{Results}

\section{Heart rate and post-exercise blood lactate concentration}

A total of 458 mean HR values were measured in 159 different horses during 110 events at 36 different venues. The number of observations per horse ranged from 1 to 23 with an average of 2.9 observations per horse. The ambient temperatures ranged from 2 to $34^{\circ} \mathrm{C}$ with WBGT indexes between 7 and 29. The HR values recorded during crosscountry tests at 2-star, 3-star and 4-star level and their distribution across specific HR zones are reported in Figure 1. The regression lines for mean HR values in relation to mean velocity and the estimated marginal means estimated by the LMM for competitions at 2-star, 3-star, 4-star and 5 -star levels are shown in Figure 2. The significant maineffects in the model of mean HR were: competition level $\left(\chi^{2}\right.$ $(3)=18.1, P<0.001)$, mean velocity $\left(\chi^{2}(1)=92.4, P<0.001\right)$, cumulative elevation $\left(X^{2}(1)=11.2, P<0.001\right)$, total distance $\left(\chi^{2}(1)=7.4, P=0.0065\right)$, number of jumping efforts $\left(\chi^{2}(1)=\right.$ 4.9, $P=0.028)$, sex $\left(X^{2}(2)=12.1, P=0.0024\right)$ and percentage of Thoroughbred blood $\left(X^{2}(1)=5.3, P=0.021\right)$. There was a significant interaction between mean velocity and percentage of Thoroughbred blood $\left(\chi^{2}(1)=7.4, P=0.0067\right)$ as well as between sex and age $\left(\chi^{2}(2)=8.6, P=0.014\right)$. For velocities $>521.3 \mathrm{~m} / \mathrm{min}$ (range of observed values: $44-593$ $\mathrm{m} / \mathrm{min}$ ), there was a significant decrease of mean HR with increasing percentages of Thoroughbred blood. In mares, the mean HR during the cross-country test decreased with 


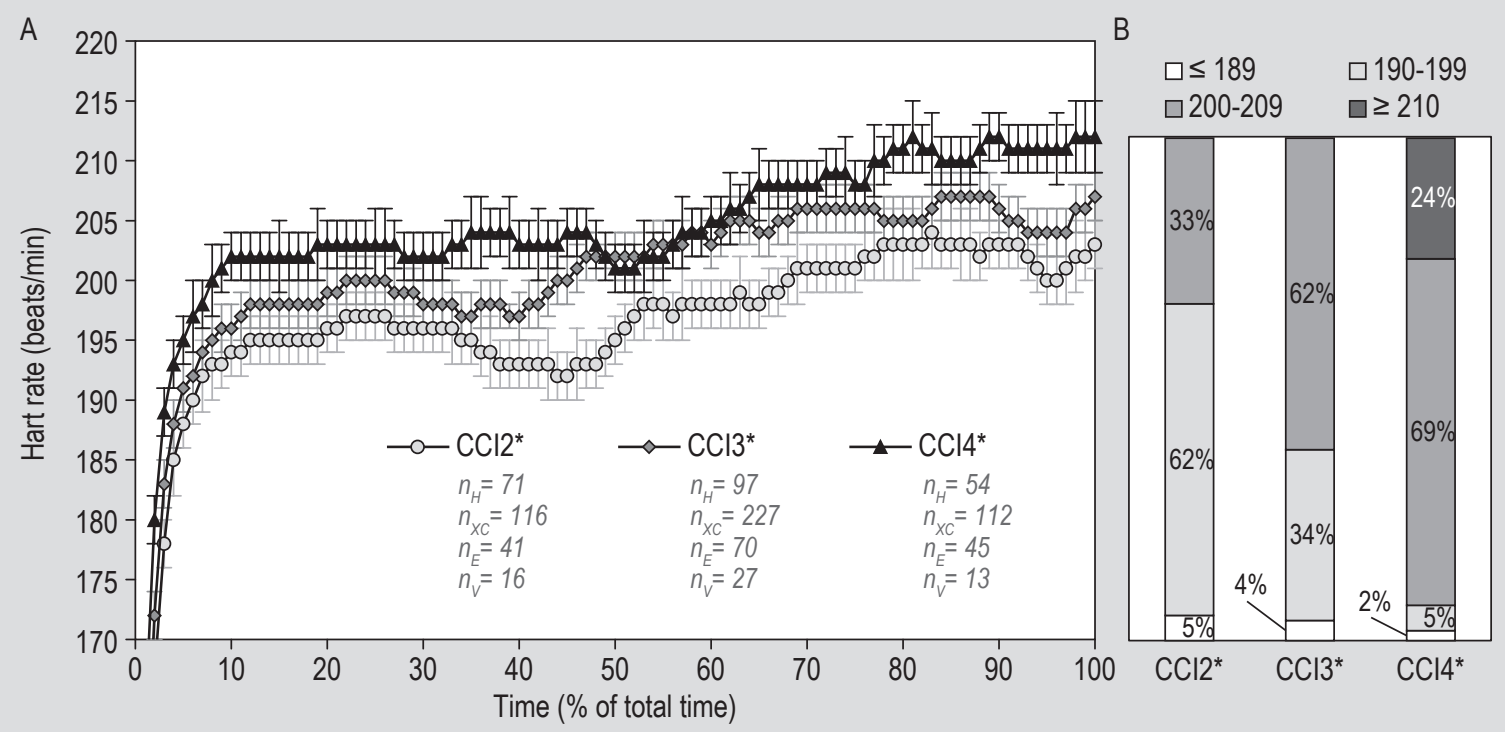

Figure 1. (A) Heart rate (estimated marginal mean \pm standard error) over time recorded during cross-country competitions at 2-star, 3-star and 4-star level. The time is reported as the percentage of total time on course. The numbers of sampled horses $\left(n_{H}\right)$, cross-country competitions $\left(n_{x C}\right)$, events $\left(n_{E}\right)$ and venues $\left(n_{v}\right)$ are reported for each level. (B) Percentage of time spent in different heart rate zones during cross-country tests at 2-star, 3-star and 4-star level. 5-star level is not shown because heart rates were only recorded during 3 competitions at that level.
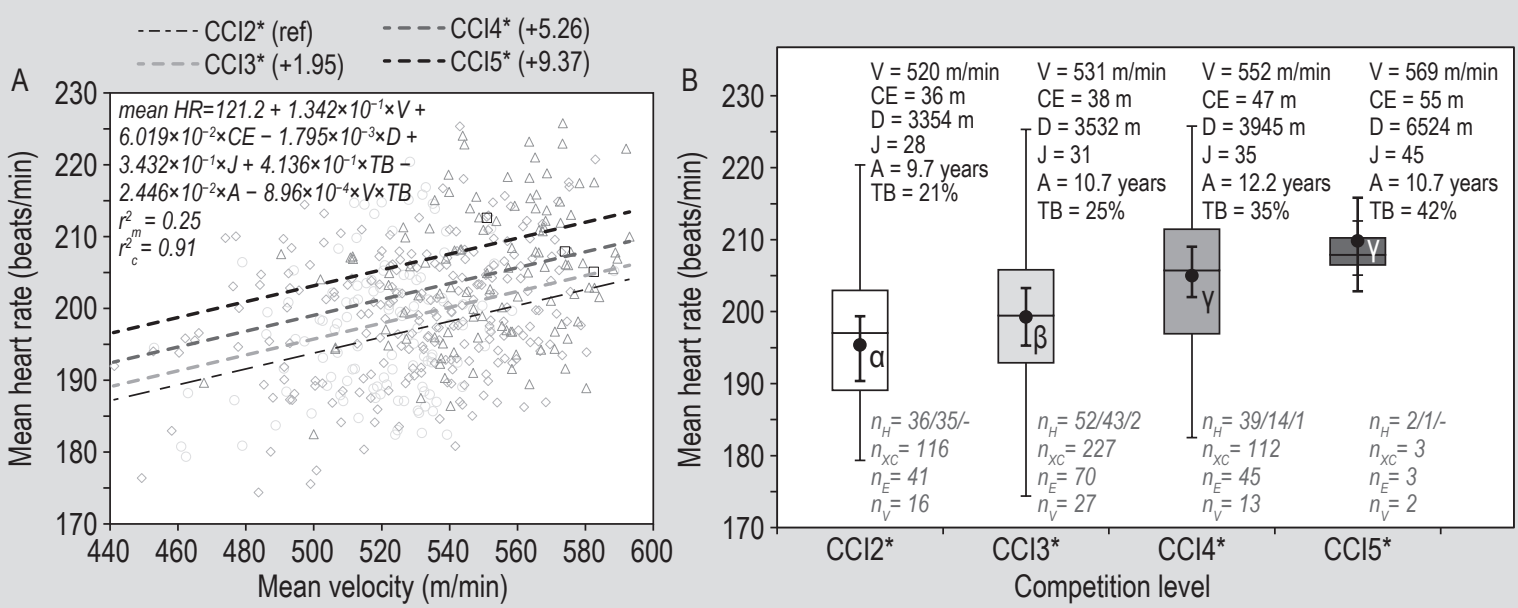

Figure 2. (A) Mean heart rate (HR) recorded during 458 cross-country tests at 2-star (circles), 3-star (rhombuses), 4-star (triangles) and 5-star (squares) level in 159 horses during 110 events at 36 different venues in relation to mean velocity. The regression lines of the linear mixed model with level, mean velocity (V), cumulative elevation (CE), total distance (D), number of jumping efforts $(\mathrm{J})$, age (A), sex and percentage of Thoroughbred blood (TB) as fixed and horse as well as event nested within venue as random effects are shown for each level. Also reported are the model formula and the marginal $\left(r^{2}{ }_{m}\right)$ and conditional $\left(r_{c}^{2}\right)$ coefficients of determination. (B) The boxplots display the distribution of mean heart rate values at different levels by indicating the median and the interquartile range. The estimated marginal means (black dots) and their $95 \%$ confidence intervals were estimated for geldings at the respective mean values of the continuous predictors for each level which are reported in the figure. Also reported are the numbers of sampled horses $\left(n_{H}\right.$, geldings/mares/stallions), cross-country competitions $\left(n_{x C}\right)$, events $\left(n_{E}\right)$ and venues $\left(n_{v}\right)$ at each level. $\alpha \beta \gamma=$ different letters indicate significant differences between levels. 
increasing age $(0.82 \pm 0.26$ beats/min decrease in mean HR with 1 year increase in age, $P<0.001)$, whereas in geldings and stallions, age did not significantly affect mean HR.

A total of $1,410 \mathrm{LAC}_{10}$ values were measured in 294 different horses during 98 events at 28 different venues. The number of observations per horse ranged from 1 to 28 with an average of 4.8 observations per horse. The ambient temperatures ranged from 2 to $34{ }^{\circ} \mathrm{C}$ with WBGT indexes between 7 and 33. Because the distribution of the LAC values was positively skewed (skewness $>1$ ) and the post-exercise blood LAC concentration is considered to be exponentially related to exercise intensity, the $\mathrm{LAC}_{10}$ values were logarithmically transformed for further analysis. Visual inspection of the normal probability plots of the residuals indicated that logarithmic transformation of $\mathrm{LAC}_{10}$ values resulted in an error distribution that was considerably closer to normality when compared to models with untransformed values. The regression lines for $\mathrm{LAC}_{10}$ values in relation to mean velocity and the estimated marginal means estimated by the LMM for competitions at 2-star, 3-star, 4-star and 5-star levels are shown in Figure 3. The significant maineffects in the model of $\log \left(\mathrm{LAC}_{10}\right)$ were: competition level $\left(\chi^{2}(3)=17.4, P<0.001\right)$, mean velocity $\left(\chi^{2}(1)=222.6\right.$, $P<0.001)$, cumulative elevation $\left(\chi^{2}(1)=22.8, P<0.001\right)$, total distance $\left(\chi^{2}(1)=16.8, P<0.001\right)$, number of jumping efforts $\left(\chi^{2}(1)=8.2, P=0.0043\right)$, percentage of Thoroughbred blood $\left(\chi^{2}(1)=22.3, P<0.001\right)$, age $\left(\chi^{2}(1)=8.9, P=0.0029\right)$ and FEI world ranking score $\left(\chi^{2}(1)=17.3, P<0.001\right)$. There was a significant interaction between mean velocity and cumulative elevation $\left(X^{2}(1)=16.8, P<0.001\right)$. Within the range of observed values of cumulative elevation (6-97 $\mathrm{m}$ ), there was a significant increase in $\mathrm{LAC}_{10}$ with increasing velocity. However, the effect of cumulative elevation decreased with increasing velocities. For velocities $>589.5$ $\mathrm{m} / \mathrm{min}$ (range of observed values: $385-607 \mathrm{~m} / \mathrm{min}$ ), the effect of cumulative elevation was no longer significant.

The total distance covered during the cross-country test and the number of jumping efforts both significantly affected $\mathrm{LAC}_{10}$ as well as mean HRs with increasing distances resulting in lower $\mathrm{LAC}_{10}$ and mean $\mathrm{HR}$ values and increasing numbers of jumping efforts resulting in higher $\mathrm{LAC}_{10}$ and mean HR values. The total distance covered during the cross-country test was significantly correlated to the mean distance between jumping efforts $(r=0.77, P<0.0001$, $\mathrm{n}=1,463$ ) which means that the number of jumping efforts did not proportionally increase with increasing distance. Consequently, the mean distance between jumping efforts (total distance/number of jumping efforts) increased with

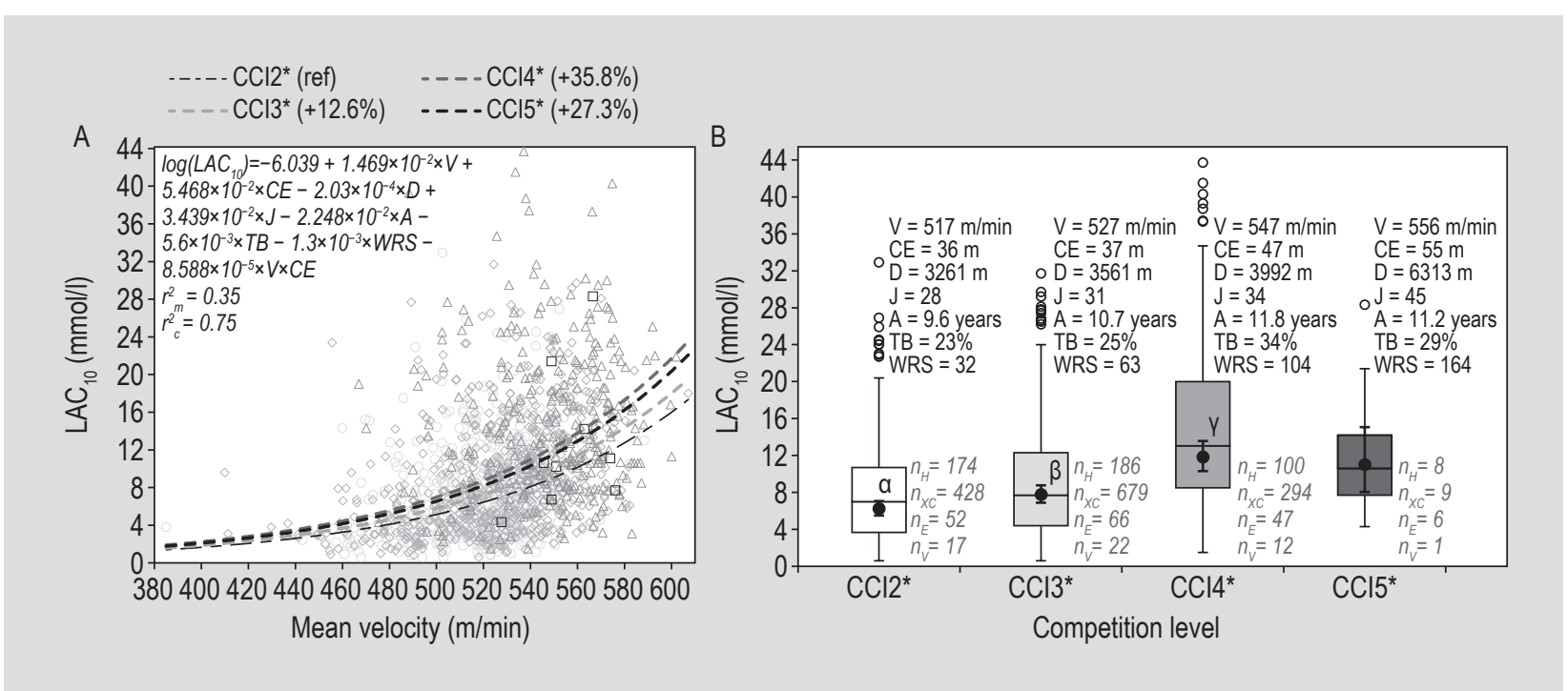

Figure 3. (A) Post-exercise blood lactate concentration measured 10 min post-exercise (LAC $\left.{ }_{10}\right)$ in relation to mean velocity during 1,410 cross-country tests at 2-star (circles), 3-star (rhombuses), 4-star (triangles) and 5-star (squares) level in 294 different horses during 98 events at 28 different venues. The regression lines of the linear mixed model fitted to the log-transformed data $\left(\log \left(\mathrm{LAC}_{10}\right)\right)$ with level, mean velocity $(\mathrm{V})$, cumulative elevation $(\mathrm{CE})$, total distance (D), number of jumping efforts (J), age (A), percentage of Thoroughbred blood (TB) and FEI world ranking score (WRS) as fixed and horse as well as event nested within venue as random effects are shown for each level. Also reported are the model formula and the marginal $\left(r^{2}{ }_{m}\right)$ and conditional $\left(r_{c}^{2}\right)$ coefficients of determination. $(B)$ The boxplots display the distribution of $L A C_{10}$ values by indicating the median and the interquartile range (IQR). Values that were larger than the upper quartile or smaller than the lower quartile by at least 1.5 times the IQR are displayed as circles. The estimated marginal means (black dots) and their $95 \%$ confidence intervals were estimated at the respective mean values of the continuous predictors for each level which are reported in the figure. Also reported are the numbers of sampled horses $\left(n_{H}\right)$, cross-country competitions $\left(n_{X C}\right)$, events $\left(n_{E}\right)$ and venues $\left(n_{V}\right)$ at each level. a $\beta y$, different letters indicate significant differences between levels. 
increasing distance and was significantly higher in long format competitions when compared to short format competitions at the same level. Including the mean distance between jumping efforts instead of distance and number of jumping efforts as fixed factor in the LMM indicated a significant effect of the mean distance between jumping efforts on $\mathrm{LAC}_{10}\left(\mathrm{X}^{2}(1)=18.6, P<0.001\right)$ and mean HR $\left(\mathrm{X}^{2}(1)=8.2, P=0.0041\right)$ with increasing mean distances between jumping efforts resulting in a decrease in $\mathrm{LAC}_{10}$ and mean HR.

\section{Heart rate recovery}

A total of 111 recovery HRs recorded in 74 different horses during 49 events at 20 different venues were analysed. The number of observations per horse ranged from 1 to 8 with an average of 1.5 observations per horse. The ambient temperatures ranged from 2 to $26^{\circ} \mathrm{C}$ with WBGT indexes between 7 and 25 . Within the first 3 min after the crosscountry test the HRs were significantly higher at higher WBGT indexes (Figure 4).

\section{Lactate disappearance}

A total of $1,025 \mathrm{LAC}_{10}$ and $\mathrm{LAC}_{30}$ values measured in 264 different horses during 96 events at 27 different venues were included for analysis of $\triangle \mathrm{LAC}$. The number of observations per horse ranged from 1 to 22 with an average of 3.9 observations per horse. The ambient temperatures ranged from 2 to $34{ }^{\circ} \mathrm{C}$ with WBGT indexes between 7 and 33 . The $L A C$ values decreased from $\mathrm{LAC}_{10}$ to $\mathrm{LAC}_{30}$ by $7.1 \pm 3.7 \mathrm{mmol} / \mathrm{l}$ which corresponds to a mean disappearance rate of $21.2 \pm 11.0 \mathrm{mmol} / \mathrm{l} / \mathrm{h}$ (range: $2.4-78.3$ $\mathrm{mmol} / \mathrm{l} / \mathrm{h}$ ) or $0.353 \mathrm{mmol} / \mathrm{l} / \mathrm{min}$. Visual inspection of the scatterplot of $\triangle \mathrm{LAC}$ in relation to $\mathrm{LAC}_{10}$ values indicated that $\triangle \mathrm{LAC}$ increased with increasing $\mathrm{LAC}_{10}$. However, at higher $\mathrm{LAC}_{10}$ values the rate of LAC removal appeared to be saturated. Reciprocal transformation of $\triangle \mathrm{LAC}$ and $\mathrm{LAC}_{10}$ resulted in a linearisation of the relationship and considerably improved the fit of a linear regression model indicating that the original data could be described by a saturation growth-rate equation in the form of $1 / \triangle \mathrm{LAC}=$ $\mathrm{a}_{0}+\mathrm{a}_{1} \times 1 / \mathrm{LAC}_{10}$ which can be transformed to $\triangle \mathrm{LAC}=$ $\alpha \times \mathrm{LAC}_{10} /\left(\beta+\mathrm{LAC}_{10}\right)$ with $\alpha=1 / \mathrm{a}_{0}$ and $\beta=\mathrm{a}_{1} / \mathrm{a}_{0}$. The LMM, fitted to the transformed data indicated that the rate of LAC removal from the blood was significantly related

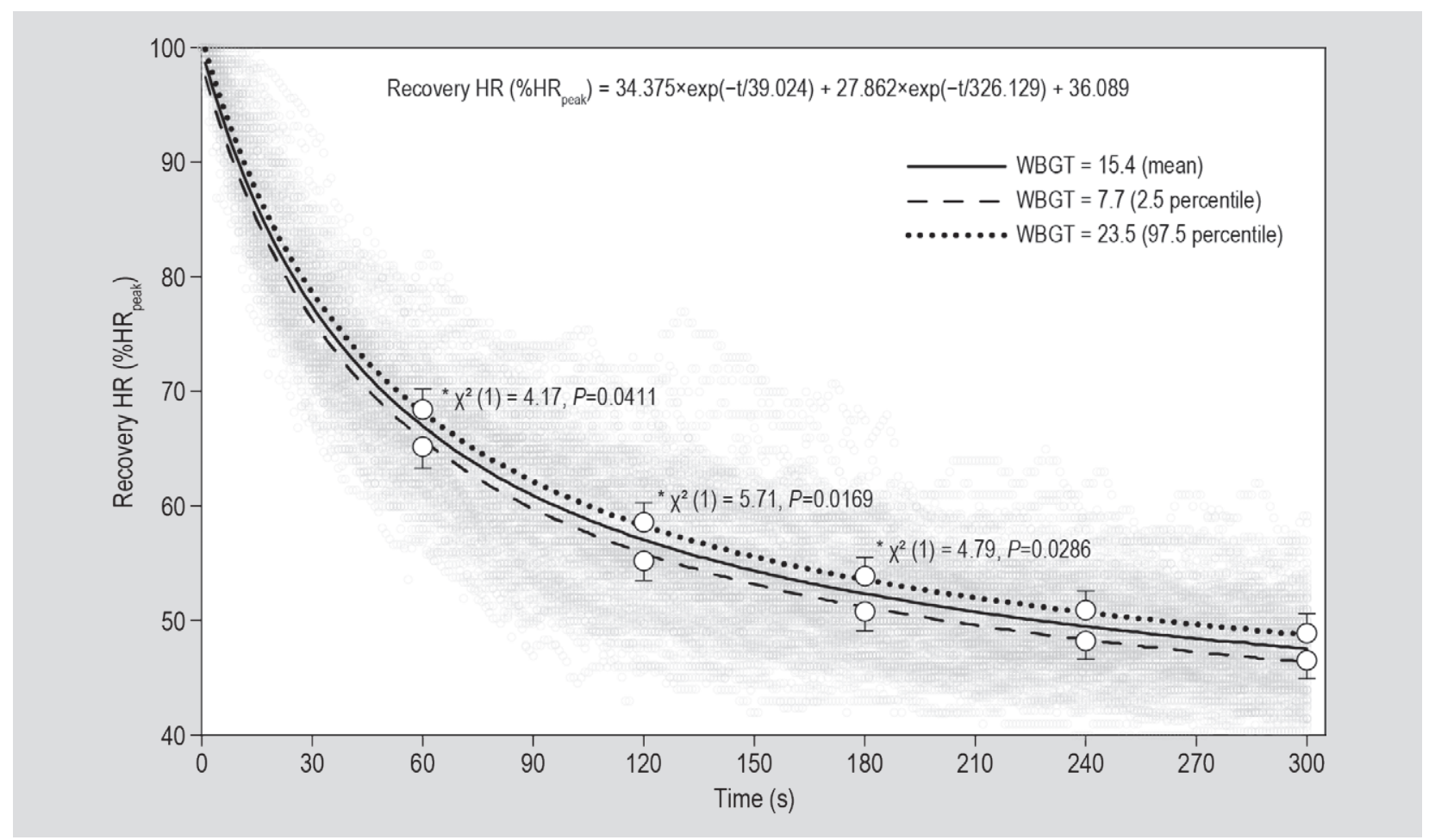

Figure 4. Post exercise heart rate (HR) values (grey circles) recorded during the first 5 min of recovery after 111 cross-country tests in 74 horses during 49 events at 20 different venues. The recovery HR is shown as percentage of peak HR reached at the end of the cross-country test (\%HR $\left.{ }_{\text {peak }}\right)$ over time. The linear mixed model was fitted to the recovery HR values calculated from the individual regression equations for each horse with wet bulb globe temperature (WBGT) as fixed effect and horse as random effect. The estimated marginal means (white circles) of recovery HRs after 60, 120, 180, 240 and 300 s of recovery and their $95 \%$ confidence intervals were calculated for WBGT indexes of 15.4 (mean), 7.7 ( 2.5 percentile) and 23.5 (97.5 percentile). The model formula is reported for the mean regression line. * Recovery HR was significantly affected by the WBGT. 
to $\mathrm{LAC}_{10}\left(\chi^{2}(1)=820.7, P<0.001\right)$ and horses with higher percentages of Thoroughbred blood exhibited significantly higher disappearance rates $\left(X^{2}(1)=4.95, P=0.0261\right)$ (Figure $5 \mathrm{~B})$. Additionally, to the LMM, a saturation growth-rate model was fitted to the original data (Figure 5A).

\section{Discussion}

\section{Heart rate and blood lactate concentration as indicators of relative exercise intensity}

The HR directly reflects the response of the autonomic nervous and cardiovascular system to exercise and demonstrates an almost linear relationship with oxygen consumption over a wide range of steady-state submaximal exercise intensities (Evans, 1985; Evans and Rose, 1988; Persson, 1983). This close relationship between HR and oxygen consumption makes HR monitoring by means of HR meters an easy and objective way of quantifying the relative intensity of exercise. The HRs recorded during cross-country competitions in the present study were very variable and individual differences have shown to explain a high amount of the observed variability. In horses, maximum HRs vary greatly between individuals and have been reported to range between approximately 210 and 240 beats/min (Evans, 1985). Different horses therefore may be exercising at very different proportions of their maximum HR at a certain HR which reduces comparability of absolute HR values between horses.

The post exercise LAC reflects the dependence on anaerobic metabolism during exercise and is exponentially related to
HR and exercise intensity (Persson, 1983). During low intensity exercise, the energy demands are primarily met by aerobic metabolism and the LAC produced within the muscle cells can be directly metabolised. When the rate of LAC production exceeds the metabolising capacity of the muscle cells, lactic acid molecules accumulate within the exercising muscle cells and diffuse into the blood where they are removed and oxidised by other tissues such as nonworking muscles and liver (Pösö, 2002). As long as the LAC production within exercising muscles do not exceed the oxidative capacity of the whole system, an equilibrium between blood LAC accumulation and blood LAC elimination leads to a steady state blood LAC concentration which, in humans, usually occurs between approximately 2 and $8 \mathrm{mmol} / \mathrm{l}$ (Billat et al., 2003). As exercise intensity increases above this threshold, anaerobic pathways for energy supply become increasingly important and the muscular LAC production rate exceeds the systemic LAC elimination rate which leads to the accumulation of LAC in blood and to an exponential increase in blood LAC concentration with further increases in exercise intensity.

The use of blood LAC concentration as marker of exercise intensity during cross-country competitions requires easy and accurate measurement of blood LAC concentration under field conditions. Portable blood LAC analysers are convenient for field use but are less accurate than benchtop analysers. Several portable analysers have been assessed with regard to their accuracy for determination of LAC concentration in equine blood. Especially at higher LAC concentrations (>10 mmol/l in whole blood; $>20 \mathrm{mmol} / \mathrm{l}$ in plasma) the accuracy of most analysers is limited and
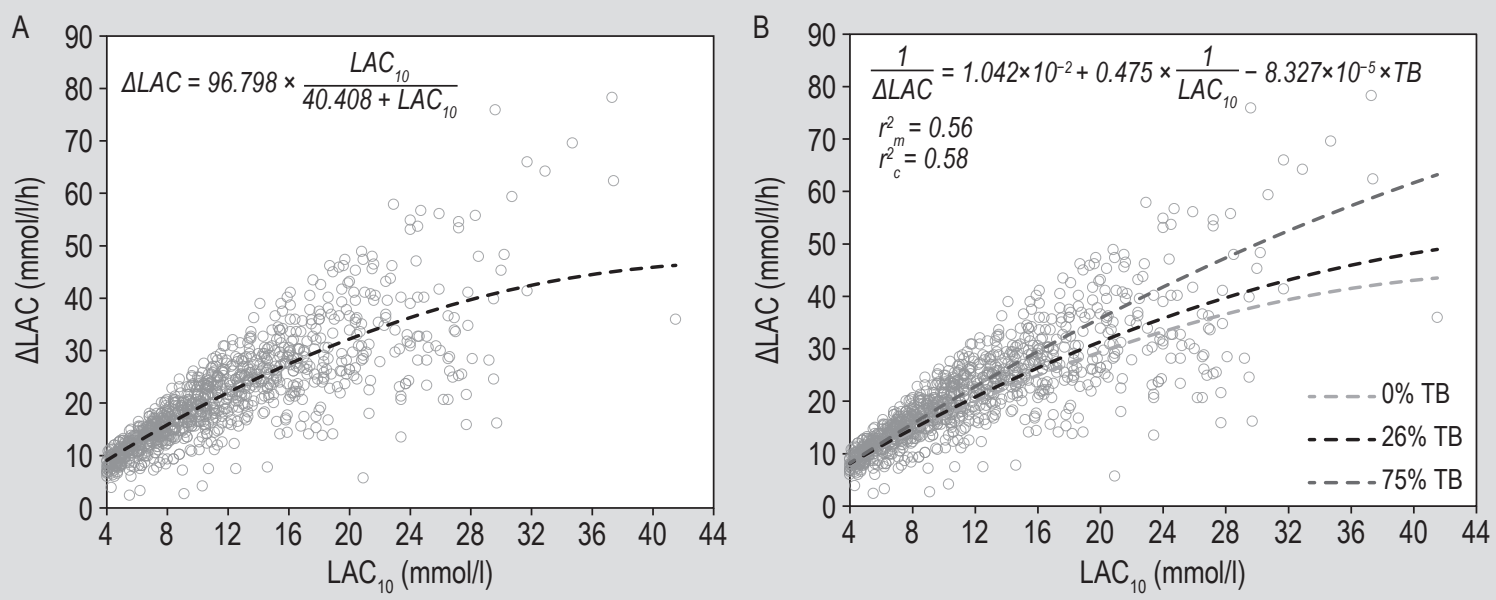

Figure 5. Rate of blood lactate disappearance $(\triangle \mathrm{LAC})$ in relation to blood lactate concentration measured 10 min post-exercise $\left(\mathrm{LAC}_{10}\right)$ following 1,025 cross-country tests in 264 horses (grey circles). The regression lines fitted by non-linear regression on the original data based on a saturation growth-rate model (A) and of the linear mixed model fitted on the transformed data (1/ALAC) with 1/LAC 10 and percentage of Thoroughbred blood (\%TB) as fixed and horse as random effect for a proportion of Thoroughbred blood of $26 \%$ (mean), $0 \%$ ( 2.5 percentile) and $75 \%$ (97.5 percentile) (B) are shown. Also reported are the model formulas and the marginal $\left(r_{m}^{2}\right)$ and conditional $\left(r_{c}^{2}\right)$ coefficients of determination. 
determination of LAC concentration in whole blood appears to be generally less accurate than in plasma (Butudom et al., 2010; Evans and Golland, 2006; Hauss et al., 2014; Lindner, 1996; Nieto et al., 2015; Sloet van OldruitenborghOosterbaan et al., 2008; Tennent-Brown et al., 2007). The photometer used for determination of post-exercise LAC in the present study was compared with another portable device that has already been validated for use in horse blood (Lactate Scout, SensLab GmbH, Leipzig, Germany) (Castagnetti et al., 2010). The coefficient of variation (CV) calculated from 41 duplicate measurements with the photometer was $4.5 \%$. The comparison between the photometer and Lactate Scout was made based on 183 measurements with LAC concentrations ranging from 0.9 to $24.0 \mathrm{mmol} / \mathrm{l}$. A Bland-Altman analysis found a bias of $-0.5 \mathrm{mmol} / \mathrm{l}$ with $95 \%$ limits of agreement of -2.1 and $1.0 \mathrm{mmol} / \mathrm{l}$ (unpublished data). The observed total error $\left(\mathrm{TE}_{\mathrm{obs}}=2 \mathrm{CV}+\right.$ Bias\%) was $21 \%$, which is lower than the allowable total error of $40 \%$ for measurement of blood lactate concentration reported by the American Society for Veterinary Clinical Pathology (ASVCP) guidelines (Harr et al., 2013). However, researchers and clinicians should be aware of the relatively high degree of measuring inaccuracy especially at high concentrations when interpreting LAC measured by portable analysers.

Another factor that needs to be considered when interpreting post-exercise LAC concentrations is the sample material that has been used. Plasma LAC concentrations are usually approximately 1.5 times greater than that of whole blood, however, the ratio between plasma and whole blood LAC concentrations depends on the LAC transport activity of the red blood cells and varies greatly between horses (Pösö, 2002; Rainger et al., 1995). Comparisons between whole blood and plasma LAC concentrations are therefore barely possible. The variable rate of LAC uptake into the red blood cells suggests that whole blood concentrations are more comparable between horses than plasma concentrations (McGowan, 2008; Pösö, 2002).

As often the case in field studies, a fixed sample time protocol was used for blood LAC determination in the present study. It has been shown that the time at which peak LAC concentrations occur following exercise are dependent upon the LAC concentration. Marlin et al. (1991) have shown that peak blood LAC concentrations occurred within 5 min post-exercise when concentrations were $10-15 \mathrm{mmol} / \mathrm{l}$ and between 5 and $10 \mathrm{~min}$ post-exercise when concentrations were $15-30 \mathrm{mmol} / \mathrm{l}$. Adopting a fixed sampling time 10 minutes post-exercise may therefore have resulted in an underestimation of the actual peak LAC concentration if the peak concentrations were below $15 \mathrm{mmol} / \mathrm{l}$.
Several individual factors whether inherited or acquired, such as the capacity of the cardiovascular system, muscle fibre composition, glycolytic enzyme activity as well as capillary and mitochondrial density may influence the HR and/or LAC-workload relationship. High endurance capacity reduces the glycolytic rate and increases the rate of LAC oxidation and thus leads to a lower blood LAC concentration at a given workload. The blood LAC concentration at a specific absolute workload therefore may be used to assess the horse's endurance capacity. Several studies have shown that HR and LAC in response to specific external workloads provide reliable indicators of fitness and are correlated to competition performance in Thoroughbred racehorses (Evans et al., 1993; Gramkow and Evans, 2006), Standardbred trotters (Casini and Greppi, 1996; Couroucé et al., 1997; Davie et al., 2002; Lindner, 2010) and eventing horses (Kirsch et al., 2019). Besides the level of physical ability, other factors such as underlying health issues may influence the HR as well as the amount of LAC accumulating during exercise. Horses that suffer from respiratory or cardiac diseases as well as horses with subclinical lameness may exhibit considerably higher HRs and/or LAC concentrations than sound horses at the same workload (Evans, 2007; Fraipont et al., 2014; Littlejohn et al., 1983; Young, 2004).

\section{Comparison of the physiological demands between classical and short competition format}

The mean HRs observed during the cross-country phase in previous investigations ranged between 165 (2-star) and 195 (4-star) beats/min (Marlin et al., 1995, Muñoz et al., 1999; Serrano et al., 2002; White et al., 1995a,b,c). The results from field studies that have been conducted in different environmental conditions and horse populations are not entirely comparable. Nevertheless, the HRs observed during cross-country competitions in the present study appeared to be considerably higher indicating higher exercise intensities compared to those observed prior to the modification of the classical competition format. Assuming an average maximum HR of approximately $210-230$ beats/min, the horses would have been working at 85-93\% (2-star), 87-95\% (3-star), 89-98\% (4-star) and 91-100\% (5-star) of maximum HR, respectively. The HR recordings throughout the crosscountry test revealed that at 4-star level the HR exceeded 200 beats/min during more than $90 \%$ of the time and even reached values above 210 beats/min during the last quarter of the course, while at 2-star and 3-star level the proportion of HRs above 200 beats/min amounted to one thirds and two thirds of the cross-country course, respectively. This would mean that the horses were working at more than $80 \%$ and partly even more than $90 \%$ of their maximum aerobic capacity for considerable proportions of the crosscountry test. 


\section{Effect of the competition level on relative exercise intensity}

In the majority of the previous studies, no statistically significant differences in HR or LAC among different competition levels or formats have been found. Andrews et al. (1995b) and White et al. (1995a,b,c) compared HRs as well as haematological and biochemical changes in horses competing either in a horse trial (only one roads-andtracks and the cross-country phase) or a 3-day event (all 4 phases) at the same level during similar environmental conditions and over similar courses. They observed that horses competing in the 3-day event experienced greater fluid and electrolyte losses than horses competing in the horse trial, but there were no significant differences in HR or post-exercise LAC even though the cross-country phase was considerably shorter in the horse trial division. Only in one study by White et al. (1995b) significant differences in HR and LAC between horses competing in horse trials at different levels were found. However, in horses competing in 3-day events, no significant differences between levels were present. Consequently, it was concluded that higher degrees of biomechanical efficiency and fitness of horses competing at upper levels may compensate higher physiological demands (Marlin et al., 1995; Muñoz et al., 1999; White et al., 1995a).

The analysis of HR and post-exercise LAC in response to cross-country competitions in the present study revealed significant differences between horses competing at different levels. Even though horses with higher performance scores exhibited lower $\mathrm{LAC}_{10}$ values, there was still an increase in relative exercise intensity from level to level indicating that increasing demands of the competition could at least not entirely be offset by higher performance capacity of horses competing at upper levels. The effect of increasing distances, velocities and numbers of jumping efforts with increasing level was controlled for by including these variables as predictors in the statistical models. The significant effect of the competition level on HR as well as post-exercise LAC therefore indicates an increase in relative exercise intensity that cannot be attributed to an increase in velocity, track length and number of jumping efforts. It has been shown that jumping exercises, even when performed at low speeds of $350 \mathrm{~m} / \mathrm{min}$, cause a significant increase in LAC concentration (Art et al., 1990; Leukeux et al., 1991). The increase in exercise intensity with increasing level may therefore reflect the increase in size and technical difficulty of the obstacles from 2-star to 5-star level.

\section{External predictors of exercise intensity}

The mean velocity was one of the major determinants of exercise intensity during cross-country competitions. An increase in velocity of $30 \mathrm{~m} / \mathrm{min}$ was associated with an increase in mean HR of approximately 3 beats/min (at a mean percentage of Thoroughbred blood of 26.5\%) and an increase in $\mathrm{LAC}_{10}$ of approximately $41 \%$. In horses with low percentages of Thoroughbred blood, the effect of an increase in velocity on mean HR was even more pronounced. In Warmbloods, each $30 \mathrm{~m} / \mathrm{min}$ increase in mean velocity was associated with a 4 beats/min increase in mean HR, whereas in horses with $75 \%$ Thoroughbred blood, the same increase in mean velocity was associated with an increase in mean HR of only 2 beats/min.

Besides the velocity, the cumulative elevation that had to be climbed during the cross-country test had a considerable impact on the intensity of exercise. Each increase in cumulative elevation of $30 \mathrm{~m}$ was associated with an increase in HR of approximately 2 beats/min and an increase in $\mathrm{LAC}_{10}$ of approximately $32 \%$ (at a mean velocity of $528 \mathrm{~m} / \mathrm{min}$ ). The effect of an increase of 30 $\mathrm{m}$ in cumulative elevation therefore was comparable to an increase of approximately $25 \mathrm{~m} / \mathrm{min}$ in mean velocity. Consequently, the terrain should be considered as an important determinant of the physiological demands of the cross-country test that is not directly defined by the competition level.

An increase in total distance was associated with a decrease in HR and LAC, whereas an increase in the number of jumping efforts was associated with an increase in HR and LAC. The observation that HR and LAC decreased with increasing distance may seem surprising. However, there was a strong positive correlation between total distance and mean distance between jumping efforts indicating that the number of jumping efforts did not proportionally increase with increasing distance. The effect of the total distance may therefore be due to the fact that at higher distances, the mean distance between jumping efforts was lower which possibly led to a decrease in exercise intensity and may explain the decrease in HR and LAC values. This hypothesis was confirmed by the fact that inclusion of the mean distance between jumping efforts as predictor into the LMM indicated a significant effect. A decrease in mean distance between jumping efforts of $20 \mathrm{~m}$ (observed range: 80-162 m) was associated with an increase in mean HR of approximately 1 beat/min and an increase in $\mathrm{LAC}_{10}$ of approximately $13 \%$.

Even though the requirements of the cross-country phase with regard to the number and size of jumping efforts as well as the required speed did not change, the efforts of course designers to build challenging cross-country courses that provide a discriminatory phase of the competition led to a considerable increase in technical difficulty of the cross-country test in recent years. The deceleration required when negotiating technically difficult obstacles consequently necessitates that the horses are galloping at higher speeds between the obstacles in order to finish the cross-country test in optimum time. In human athletes, it is generally accepted that frequent changes of speed and 
direction considerably increase the energy demands of exercise when compared to running at constant speed (Di Prampero et al., 2005). The observation that a decrease in the mean distance between jumping efforts considerably increased the exercise intensity suggests that this may be even more important during the cross-country phase of short format competitions in which the distance between jumping efforts is considerably shorter and the opportunity for muscle recovery between jumping efforts is reduced (Marlin, 2014).

\section{Internal predictors of exercise intensity}

It has been argued that the decreased emphasis on the speed and endurance aspect of eventing that was accompanied with the modification of the competition format also had consequences for the selection of appropriate horses and the composition of the eventing horse population. As the inherent fitness and stamina of Thoroughbred horses made them ideally suited for the classical eventing competition, Thoroughbreds or Thoroughbred-crosses have long been the most represented breed in high level eventing competitions (Marlin, 2014). The modification of the eventing competition and the increasing emphasis on the dressage test was accompanied by a growing popularity of Warmbloods as their gait and conformation make it easier for them to achieve superior dressage scores (Schaeffer, 2014). Events such as the 2014 World Equestrian Games in Normandy where many horses could not finish the crosscountry course because its ground conditions and design demanded a high level of endurance, however, led to a change in perception. The fact that the top five horses competing in the 2014 World Equestrian Games were horses with a high percentage of Thoroughbred blood raised the question of whether the impact attributed to inherited or acquired endurance capacity for success in modern eventing competitions should be considered to be more important than previously thought and that the nature of the modern course design puts possibly even more emphasis on cardiovascular capacity.

The population of horses investigated in this study showed a relatively broad variety of Thoroughbred proportions. However, $75 \%$ of horses had a proportion of Thoroughbred blood $<50 \%$ with higher mean percentages of Thoroughbred blood among horses competing at 4-star and 5-star level (38 and 33\%) when compared to 2-star and 3-star level (23 and 25\%). The percentage of Thoroughbred blood had a significant effect on post-exercise LAC and HR. Horses with $75 \%$ Thoroughbred blood had approximately 4 beats $/ \mathrm{min}$ lower HRs (at a mean velocity of $534 \mathrm{~m} / \mathrm{min}$ ) and approximately $34 \%$ lower $\mathrm{LAC}_{10}$ values compared to Warmbloods. The effect of the percentage of Thoroughbred blood on mean HR increased with increasing velocities. At a velocity of $570 \mathrm{~m} / \mathrm{min}$, the difference in mean $\mathrm{HR}$ between a horse with 75\% Thoroughbred blood and a warmblood horse amounted to approximately 7 beats $/ \mathrm{min}$.

Besides the percentage of Thoroughbred blood, the age of the investigated horses had a significant effect on postexercise LAC and mean HR as well. A 5 years increase in age was associated with a decrease in $\mathrm{LAC}_{10}$ of $11 \%$. In mares, the mean $\mathrm{HR}$ during the cross-country test decreased with increasing age with an approximately 4 beats/min decrease in mean HR with each 5 years increase in age, whereas in geldings and stallions, there was no significant effect of age on mean HR. The decrease in HR and LAC with increasing age may be explained by an increase in exercise capacity with increasing age as the result of several years of experience and training.

The horse's performance levels were rated based on the total FEI world ranking score achieved during one competitive season. Horses with higher scores had significantly lower post-exercise LAC values. An increase in the score by 100 units (observed range: 0-370) was associated with a decrease in $\mathrm{LAC}_{10}$ of approximately $12 \%$. The world ranking scores had no significant effect on the mean HR. The individual variability in the $H R$ values may have been too high to detect significant differences between horses with different scores.

\section{The effect of climatic conditions}

Previous studies have shown that the speed and endurance test of 3-day events induces significant fluid losses and electrolyte and biochemical changes that were more pronounced in hot and humid environments (Andrews et al., 1995a; Ecker and Lindinger, 1995; Foreman et al., 2004). In the present study, the climatic conditions were evaluated by including the WBGT index as fixed effect into the statistical models, however the WBGT was approximated from ambient temperature and relative humidity not taking wind speed and solar radiation into account. Moreover, mean values were recorded only once during each competition and therefore may serve only as rough estimates. The WBGT index did not significantly affect post-exercise LAC or mean HR during the crosscountry test. Therefore, the climatic conditions apparently had no significant effect on the physiological demands of the cross-country tests. However, the HR recovery following the cross-country test was significantly affected by the WBGT index with horses competing in hot and humid conditions exhibiting higher recovery HRs than those competing in cooler conditions. The climatic conditions during the investigated events were mainly moderate with WBGT indexes ranging from 7 to 33 . According to the recommendations of the FEI (FEI Eventing Memorandum, 2015), additional precautions to reduce heat load and prevent overheating are required at WBGT indexes above 28. WBGT values above 32 are considered to be hazardous and modifications of the competition are recommended. In 
this study, WBGT values above 28 were recorded at only 5 events and above 32 at only 1 event. It may therefore be possible, that more challenging climatic conditions would have had a measurable effect on HR and/or LAC values.

\section{Heart rate recovery}

The underlying mechanisms of HR recovery after exercise are still not completely understood. The initially fast decrease in HR mainly seems to arise from a rapid cardiac parasympathetic reactivation after cessation of exercise whereas the further slow decrease is probably determined by a progressive sympathetic withdrawal (Pierpont and Voth, 2004). It has been shown that the coordinated interaction of the parasympathetic and sympathetic parts of the autonomic nervous system during HR recovery is best described by a bi-exponential model with a fast initial and a slower subsequent decrease in human athletes (Pierpont and Voth, 2004) as well as horses (Bitschnau et al., 2010; Rugh et al., 1992). Application of the bi-exponential model to the HR data measured during recovery following crosscountry tests in the present study provided a very good prediction of the HR decrease explaining on average $96 \pm 3 \%$ of the variance in the data. Because periods of less than 5 min were considered as too short to enable reliable analysis of HR recovery, only HR data that were recorded for at least $5 \mathrm{~min}$ were considered for analysis. In most cases the HR monitors were quickly removed after finishing the cross-country test in order to allow for an effective cooling of the horses and the HR data could therefore not be used for analysis of $H R$ recovery.

In human athletes HR recovery after exercise is believed to be a useful parameter to monitor training status or as indicator of overtraining and fatigue (Lamberts et al., 2009, 2010). Also, in equine athletes post-exercise HR recovery has been shown to be associated with indicators of performance (Bitschnau et al., 2010; Hada et al., 2006; Kirsch et al., 2019). The recovery HRs measured after the cross-country tests in the present study were not significantly affected by any of the tested predictors of external or internal exercise intensity, except for the WBGT index. The effect of the WBGT index was significant, even though the climatic conditions during the investigated events were moderate (WBGT index between 7 and 25). However, with a mean difference in $\% \mathrm{HR}_{\text {peak }}$ of approximately $3 \%$ (which corresponds to a difference of 6 beats/min at a $\mathrm{HR}_{\text {peak }}$ of 200 beats $/ \mathrm{min}$ ) between a WBGT index of 7.7 and 23.5 , the effect size was relatively small. The cardiovascular system acts as a major thermoregulatory effector by increasing the cardiac output and redistributing the blood flow to the skin and respiratory tract to enable heat dissipation (Hodgson, 2014). The higher HRs during recovery at more challenging climatic conditions therefore may be the result of increased heat stress that is associated with an increase in sympathetic activity and a rise in HR and stroke volume (Rowell, 1986).

\section{Lactate disappearance rates}

Based on the analysis of the disappearance rates of blood LAC concentrations in Thoroughbreds after a standardised treadmill exercise at varying intensities, Marlin et al. (1991) concluded that LAC disappearance during recovery is best described as a linear process. In the same study, it has been shown that the LAC disappearance following exercise was virtually independent of exercise intensity or concentration and that the removal of LAC from blood appears to be a saturable process with saturation occurring at peak blood LAC concentrations of approximately $10 \mathrm{mmol} / \mathrm{l}$.

In the present study, LAC was only measured twice, 10 min and 30 min post-exercise. Nevertheless, assuming that LAC disappearance is linear and that peak concentrations were already reached before or approximately at the first sampling, the difference in blood LAC concentration between the first and the second sampling should provide a reasonable estimate of the LAC disappearance rate following the cross-country test.

In contrast to what has been previously observed in Thoroughbreds, the LAC disappearance rates observed in eventing horses following the cross-country test were concentration-dependent with disappearance rates increasing by approximately $0.8 \%$ with each $1 \%$ increase in $\mathrm{LAC}_{10}$ (which corresponds to an increase of approximately 1.7 to $1.2 \mathrm{mmol} / \mathrm{l} / \mathrm{h}$ for each $1 \mathrm{mmol} / \mathrm{l}$ increase in $\mathrm{LAC}_{10}$ at concentrations between 4 and $40 \mathrm{mmol} / \mathrm{l})$. A direct correlation between rates of LAC removal from blood and blood LAC concentration has also been shown in dogs (Issekutz et al., 1976) and humans (Bonen et al., 1979). The fact that the relationship between LAC disappearance rates and concentrations could be appropriately described by a saturation growth-rate equation suggests that the rate of LAC removal is saturable, however, based on the data analysed within this study at considerably higher rates than proposed by Marlin et al. (1991).

It has been shown that LAC removal is accelerated by low to moderate activity during the recovery period after exercise (Lovell and Rose, 1995; Marlin et al., 1987). Usually, the horses investigated in this study underwent an active recuperation at walk between the first and the second sampling. However, because the activity during recovery was not controlled it may have varied between horses depending on their individual cool-down routines which may have influenced the rates of LAC disappearance.

The LAC disappearance rates after cross-country competitions were significantly higher in horses with high percentages of Thoroughbred blood which may 
be associated with a higher oxidative capacity in these horses. In horses, the main route for LAC removal from blood following exercise is the oxidation of lactic acid in skeletal muscle fibres (Marlin et al., 1991). The rate of LAC disappearance therefore depends on the oxidative capacity of muscles. It has been shown that Thoroughbred racehorses have a significantly higher overall oxidative phosphorylation capacity (measured by high resolution respirometry) than Warmbloods and that the oxidative capacity was even increased after several weeks of aerobic training (Serteyn et al., 2016). Another factor which may explain the higher LAC disappearance rates in horses with high percentages of Thoroughbred blood may be the high activity of monocarboxylate transporters which increases the uptake of LAC into red blood cells (Mykkänen et al., 2010). During exercise, red blood cell space may account for up to approximately $60 \%$ of the blood volume (Pösö, 2002). After exercise, the proportion of red blood cells in the total blood volume decreases. Even if LAC is measured in whole blood, changes in packed cell volume between the first and the second sampling therefore may have led to higher $\triangle \mathrm{LAC}$ values in horses with higher LAC uptake into red blood cells.

\section{Conclusions}

The high amount of data that has been measured in a large group of horses at variable stages of experience and performance in response to various competitions under different environmental conditions enabled to build comprehensive models of HR and post-exercise LAC including several external and internal factors determining the physiological demands of cross-country tests. The resulting models may be used to predict HR and post-exercise LAC values that can be expected in response to specific competition conditions which may be useful in planning competitions especially under difficult environmental conditions. Furthermore, comparison between individual values that have been measured in a certain horse under certain conditions and those that were predicted from the model may be useful to evaluate the horse's individual state of training and fitness.

Even if there was considerable variation between horses sampled at different occasions, the results of this study indicate that despite the shorter overall exercise duration, the intensity of exertion encountered by the horses during modern cross-country tests might be even higher when compared to the classical format. On the assumption that the modified format requires less physical ability, it might have seemed obvious for riders to spend more time to prepare their horses for the technical requirements of the dressage and show-jumping phases while paying less attention to physical fitness, especially endurance. In horses that are not appropriately prepared for the demands of the cross-country test, early onset of fatigue may considerably increase the risk of injury. This is especially important in view of the high contribution of anaerobic metabolism as indicated by high LAC concentrations contributing to acidosis that may be associated with muscle fatigue and a reduced recovery interval between jumping efforts (Marlin, 2014). The results of this study therefore imply even more importance of an adequate cardiovascular conditioning of eventing horses in order to prevent injuries which may be even more important for horses with low percentages of Thoroughbred blood as these horses appear be at a disadvantage with regard to their inherent performance capacity.

\section{Acknowledgements}

This research was conducted within the scope of the 'performance monitoring programme' of the German Olympic Committee for Equestrian Sports which is funded by the German Olympic Sports Confederation (DOSB).

\section{Conflict of interest}

The authors declare no potential conflicts of interests.

\section{References}

Andrews, F.M., Geiser, D.R., White, S.L., Williamson, L.H., Maykuth, P.L. and Green, E.M., 1995b. Haematological and biochemical changes in horses competing in a 3-star horse trial and 3-day-event. Equine Veterinary Journal, Suppl. 20: 57-63.

Andrews, F.M., Ralston, S., Williamson, L.H., Maykuth, P.L., White, S.L. and Provenza, M., 1995a. Weight loss, water loss and cation balance during the endurance test of a 3-day event. Equine Veterinary Journal, Suppl. 18: 294-297.

Arnold, T.W., 2010. Uninformative parameters and model selection using Akaike's information criterion. Journal of Wildlife Management 74: 1175-1178.

Art., T., Amory, H., Desmecht, D. and Lekeux, P., 1990. Effect of show jumping on heart rate, blood lactate and other plasma biochemical values. Equine Veterinary Journal, Suppl. 9: 78-82.

Barton, K., 2018. MuMIn: multi-model inference. R package version 1.40.4. Available at: https://CRAN.R-project.org/package=MuMIn

Bates, D., Martin, M., Bolker, B. and Walker, S., 2015. Fitting linear mixed-effects models using lme4. Journal of Statistical Software 67: 1-48.

Billat, V.L., Sirvent, P., Py, G. and Koralsztein, J., 2003. The concept of maximal lactate steady state. Sports Medicine 33: 407-426.

Bitschnau, C., Wiestner, T., Trachsel, D.S., Auer, J.A. and Weishaupt, M.A., 2010. Performance parameters and post exercise heart rate recovery in Warmblood sport horses of different performance levels. Equine Veterinary Journal, Suppl. 38: 17-22.

Bonen, A., Campbell, C.J., Kirby, R.L. and Belcastro, A.N., 1979. A multiple regression model for blood lactate removal in man. Pflügers Archiv 380: 205-210. 
Burnham, K.P. and Anderson, D.R., 2002. Model selection and multimodel inference: a practical information-theoretic approach, $2^{\text {nd }}$ ed. Springer, New York, NY, USA.

Butudom, P., Foreman, J.H., Kline, K.H. and Whittem, E.L., 2010. Validation and comparison of two methods of measuring lactate in equine plasma. Equine Veterinary Journal, Suppl. 38: 155-160.

Casini, L. and Greppi, G.F., 1996. Correlation of racing performance with fitness parameters after exercise tests on treadmill and on track in Standardbred racehorses. Pferdeheilkunde 12(4): 466-469.

Castagnetti, C., Pirrone, A., Mariella, J. and Mari, G., 2010. Venous blood lactate evaluation in equine neonatal intensive care. Theriogenology 73: 343-357.

Couroucé, A., Chatard, J.C. and Auvinet, B., 1997. Estimation of performance potential of Standardbred trotters from blood lactate concentrations measured in field conditions. Equine Veterinary Journal 29: 365-369.

Davie, A.J., Priddle, T.L. and Evans, D.L., 2002. Metabolic responses to submaximal field exercise tests and relationships with racing performance in pacing Standardbreds. Equine Veterinary Journal, Suppl. 34: 112-115.

Di Prampero, P.E., Fusi, S., Sepulcri, L., Morin, J.B., Belli, A. and Antonutto, G., 2005. Sprint running: a new energetic approach. Journal of Experimental Biology 208: 2809-2816.

Ecker, G.L. and Lindinger, M.I., 1995. Water and ion losses during the cross-country phase of eventing. Equine Veterinary Journal, Suppl. 20: 111-119.

Evans, D.L. and Golland, L.C., 2006. Accuracy of Accusport for measurement of lactate concentrations in equine blood and plasma. Equine Veterinary Journal 28: 398-402.

Evans, D.L. and Rose R.J., 1986. Method of investigation of the accuracy of four digitally-displaying heart rate meters suitable for use in the exercising horse. Equine Veterinary Journal 18(2): 129-132.

Evans, D.L. and Rose R.J., 1988. Cardiovascular and respiratory responses in thoroughbred horses during treadmill exercise. Journal of Experimental Biology 134: 397-408.

Evans, D.L. and Rose, R.J., 1987. Maximum oxygen uptake in racehorses: changes with training state and prediction from submaximal cardiorespiratory measurements. In: Gillespie, J.R. and Robinson, N.E. (eds.) Equine exercise physiology 2. ICEEP Publications, Davis, CA, USA, pp. 52-67.

Evans, D.L., 1985. Cardiovascular adaptations to exercise and training. Veterinary Clinics of North America: Equine Practice 1: 513-531.

Evans, D.L., 2007. Physiology of equine performance and associated tests of function. Equine Veterinary Journal 39: 373-383.

Evans, D.L., Harris, R.C. and Snow, D.H., 1993. Correlation of racing performance with blood lactate and heart rate after exercise in Thoroughbred horses. Equine Veterinary Journal 25: 441-445.

Fédération Equestre Internationale (FEI), 2015. Eventing memorandum, $8^{\text {th }}$ ed. FEI, Lausanne, Switzerland, pp. 59. Available at: https://inside. fei.org/fei/disc/eventing/rules

Fédération Equestre Internationale (FEI), 2020. Eventing rules 2020, $25^{\text {th }}$ ed. FEI, Lausanne, Switzerland, pp. 81. Available at: https:// inside.fei.org/fei/disc/eventing/rules
Foreman, J.H., Waldsmith, J.K. and Lalum, R.B., 2004. Physical, acidbase and electrolyte changes in horses competing in training, preliminary and intermediate horse trials. Equine and Comparative Exercise Physiology 1: 99-105.

Fraipont, A., Van Erck, E., Ramery, E., Richard, E., Denoix, J., Lekeux, P. and Art, T., 2014. Subclinical diseases underlying poor performance in endurance horses: diagnostic methods and predictive tests. Veterinary Records 169: 154.

Gramkow, H.L. and Evans, D.L., 2006. Correlation of race earnings with velocity at maximal heart rate during a field exercise test in Thoroughbred racehorses. Equine Veterinary Journal, Suppl. 36: 118-122.

Hada, T., Ohmura, H., Mukai, K., Eto, D., Takahashi, T. and Hiraga, A., 2006. Utilisation of the time constant calculated from heart rate recovery after exercise for evaluation of autonomic activity in horses. Equine Veterinary Journal, Suppl. 36: 141-145.

Harr, K.E., Flatland, B., Nabity, M. and Freeman, K.P., 2013. ASVCP guidelines: allowable total error guidelines for biochemistry. Veterinary Clinical Pathology 42: 424-436.

Hauss, A.A., Stablein, C.K., Fisher, A.L., Greene, H.M. and NoutLomas, Y.S., 2014. Validation of the lactate plus lactate meter in the horse and its use in a conditioning program. Journal of Equine Veterinary Science 34: 1064-1068.

Hebenbrock, M., Düe, M., Holzhausen, H., Sass, A., Stadler, P. and Ellendorff, F., 2005. A new tool to monitor training and performance of sport horses using Global Positioning System (GPS) with integrated GSM capabilities. Deutsche Tierärztliche Wochenschrift 112: 262-265.

Hodgson, D.R., 2014. Thermoregulation. In: Hodgson, D.R., McGowan, C. and McKeever, K.H. (eds.). The athletic horse: principles and practice of equine sports medicine. Saunders, Philadelphia, PA, USA, pp. 108-124.

Hothorn, T., Bretz, F. and Westfall, P., 2008. Simultaneous inference in general parametric models. Biomedical Journal 50: 346-363.

Issekutz, B., Shaw, W.A.S. and Issekutz, A.C., 1976. Lactate metabolism in resting and exercising dogs. Journal of Applied Physiology 40: 312-319.

Jeffcott, L.B. and Kohn, C.W., 1999. Contributions of equine exercise physiology research to the success of the 1996 Equestrian Olympic Games: a review. Equine Veterinary Journal, Suppl. 30: 347-355.

Kirsch, K., Düe, M., Holzhausen, H. and Sandersen, C., 2019. Correlation of competition performance with heart rate and blood lactate response during interval training sessions in eventing horses. Comparative Exercise Physiology 15: 187-197.

Kusunose, R. and Takahashi, T., 2002. Reliability of equipilot for measuring aerobic fitness in racehorses. Journal of Equine Science 13: $117-121$

Lamberts, R.P., Swart, J., Capostagno, B., Noakes, T.D. and Lambert, M.I., 2010. Heart rate recovery as a guide to monitor fatigue and predict changes in performance parameters. Scandinavian Journal of Medicine and Science in Sports 20: 449-457.

Lamberts, R.P., Swart, J., Noakes, T.D. and Lambert, M.I., 2009. Changes in heart rate recovery after high-intensity training in well-trained cyclists. European Journal of Applied Physiology 105: 705-713. 
Lekeux, P., Art, T., Linden, A., Desmecht, D. and Amory, H., 1991. Heart rate, hematological and serum biochemical responses to show jumping. In: Gillespie, J.R. and Robinson, N.E. (eds.) Equine exercise physiology 3. ICEEP Publications, Davis, CA, USA, pp. 385-390.

Lenth, R., 2019. emmeans: Estimated Marginal Means, aka LeastSquares Means. R package version 1.3.3. Available at: https:// CRAN.R-project.org $/$ package $=$ emmeans

Lindner, A. and Brand, A., 2020. Global positioning system-determined and stopwatch-determined running speeds of horses differ. Journal of Equine Veterinary Science 84: 102871.

Lindner, A., 1996. Measurement of plasma lactate concentration with Accusport. Equine Veterinary Journal 28: 403-405.

Lindner, A.E., 2010. Relationships between racing times of Standardbreds and V4 and V200. Journal of Animal Science 88: 950-954.

Littlejohn, A., Bowles, F. and Aschenborn, G., 1983. Cardiorespiratory adaptations to exercise in riding horses with chronic lung disease. In: Snow, D.H., Persson, S.G.B. and Rose, R.J. (eds.) Equine exercise physiology. Granta Editions, Cambridge, UK, pp. 33.

Long, J.A., 2019. Interactions: comprehensive, user-friendly toolkit for probing interactions. R package version 1.1.0. Available at: https:// cran.r-project.org/package $=$ interactions

Lovell, D.K. and Rose, R.J., 1995. Effects of post exercise activity on recovery from maximal exercise. Equine Veterinary Journal, Suppl. 18: 188-190.

Marlin, D., 2009. Heat, humidity and horse welfare in the Olympic Games: learning from history. Veterinary Journal 182: 373-374.

Marlin, D.J., 2014. Exercise physiology of eventing. Available at: http:// davidmarlin.co.uk/portfolio/exercise-physiology-of-eventing/

Marlin, D.J., Harris, P.A., Schroter, R.C., Harris, R.C., Roberts, C.A., Scott, C.M., Orme, C.E., Dunnett, M., Dyson, S.J., Barrelet, F., Williams, B., Marr, C.M. and Casas, I., 1995. Physiological, metabolic and biochemical responses of horses competing in the speed and endurance phase of a $\mathrm{CCI}^{* * * *}$ 3-day-event. Equine Veterinary Journal, Suppl. 20: 37-46.

Marlin, D.J., Harris, R.C. and Snow, D.H., 1991. Rates of blood lactate disappearance following exercise of different intensities. In: Gillespie, J.R. and Robinson, N.E. (eds.) Equine exercise physiology 3. ICEEP Publications, Davis, CA, USA, pp. 188-195.

Marlin, D.J., Harris, R.C. Harman J.C. and Snow, D.H., 1987. Influence of post-exercise activity rates on muscle and blood lactate disappearance in the thoroughbred horse. In: Gillespie, J.R. and Robinson, N.E. (eds.) Equine exercise physiology 2. ICEEP Publications, Davis, CA, USA, pp. 321-331.

McGowan, C., 2008. Clinical pathology in the racing horse: the role of clinical pathology in assessing fitness and performance in the racehorse. Veterinary Clinics: Equine Practice 24: 405-421.

Monette, G., 2015. vif.lme: Variance Inflation Factors for Mixed Models. R package version 0.1.3.

Muñoz, A., Riber, C., Santisteban, R., Rubio, M.D., Agüera, E.I. and Castejón, F.M., 1999. Cardiovascular and metabolic adaptations in horses competing in cross-country events. Journal of Veterinary Medicine Science 61: 13-20.
Mykkänen, A.K., Hyyppä, S., Pösö, A.R., Ronéus, N. and EssénGustavsson, B., 2010. Immunohistochemical analysis of MCT1 and CD147 in equine skeletal muscle fibres. Research in Veterinary Science 89: 432-437.

Nieto, J.E., Dechant, J.E., Le Jeune, S.S. and Snyder, J.R., 2015. Evaluation of 3 handheld portable analyzers for measurement of L-lactate concentrations in blood and peritoneal fluid of horses with colic. Veterinary Surgery 44: 366-372.

Persson, S.B.G., 1983. Evaluation of exercise tolerance and fitness in the performance horse. In: Snow, D.H., Persson, S.B.G. and Rose, R.J. (eds.) Equine exercise physiology. Granta Editions, Cambridge, UK, pp. 441-457.

Pierpont, G.L. and Voth, E.J., 2004. Assessing autonomic function by analysis of heart rate recovery from exercise in healthy subjects. American Journal of Cardiology 94: 64-68.

Pösö, A.R., 2002. Monocarboxylate transporters and lactate metabolism in equine athletes: a review. Acta Veterinaria Scandinavica 43: 63-74.

Rainger, J.E., Evans, D.L., Hodgson, D.R. and Rose, R.J., 1995. Distribution of lactate in plasma and erythrocytes during and after exercise in horses. British Veterinary Journal 151: 299-310.

Rowell, L.B., 1986. Human circulation: regulation during physical stress. Oxford University Press, New York, NY, USA.

Rugh, K.S., Jiang, B., Hatfield, D.G., Garner, H.E. and Hahn, A.W., 1992. Mathematical modelling of post-exercise heart rate recovery in ponies. Biomedical Sciences Instrumentation 28: 151-156.

Schaeffer, W., 2014. Training the event horse. In: Hodgson, D.R. and Rose, R.J. (eds.) The athletic horse. WB Saunders, Philadelpha, PA, USA, pp. 321-330.

Serrano, M.G., Evans, D.L. and Hodgson, J.L., 2002. Heart rate and blood lactate responses during exercise in preparation for eventing competition. Equine Veterinary Journal, Suppl. 34: 135-139.

Serteyn, D., Ceusters, J., Nonnenmacher, S., Kirsch, K., MouithysMickalad, Franck, T., Lejeune, J.P. and Sandersen, C., 2016. Mitochondrial function and aerobic capacity assessed by high resolution respirometry in Thoroughbred horses. Comparative Exercise Physiology 12: 67-73.

Sloet van Oldruitenborgh-Oosterbaan, M.M., Van den Broek, E.T.W. and Spierenburg, A.J., 2008. Evaluation of the usefulness of the portable device Lactate Pro for measurement of lactate concentrations in equine whole blood. Journal of Veterinary Diagnostic Investigation 20: 83-85.

Tennent-Brown, B.S., Wilkins, P.A., Lindborg, S., Russell, G. and Boston, R.C., 2007. Assessment of a point-of-care lactate monitor in emergency admissions of adult horses to a referral hospital. Journal of Veterinary Internal Medicine 21: 1090-1098.

White, S.L., Williamson, L.H., Maykuth, P.L., Cole, S. and Andrews, F., 1995a. Heart rate and lactate concentration during two different cross-country events. Equine Veterinary Journal, Suppl. 18: 463-467.

White, S.L., Williamson, L.H., Maykuth, P.L., Cole, S. and Andrews, F., 1995b. Heart rate response and plasma lactate concentrations of horses competing in the cross-country phase of combined training events. Equine Veterinary Journal, Suppl. 20: 47-51.

White, S.L., Williamson, L.H., Maykuth, P.L., Cole, S. and Andrews, F., 1995c. Heart rate response and plasma lactate concentrations of horses competing in the speed and endurance phase of combined training events. Equine Veterinary Journal, Suppl. 20: 52-56. 
Young, L., 2004. Diseases of the heart and vessels. In: Hinchcliff, K.W., Kaneps, A.J. and Geor, R.J. (eds.) Equine sports medicine and surgery. Saunders, New York, NY, USA, pp. 727.
Zuur, A.F., Ieno, E.N. and Elphick, C.S., 2010. A protocol for data exploration to avoid common statistical problems. Methods in Ecology and Evolution 1:3-14. 